\title{
Parametric Investigation of Wettability Alteration of Reservoir Rocks by Asphaltene Deposition: Experimental and Modeling Approaches
}

\section{Bagheri Vanani M, Khodapanah E* and Tabatabaei-Nezhad SAR}

Faculty of Petroleum and Natural Gas Engineering, Sahand Oil and Gas Research Institute, Sahand University of Technology, Iran

*Corresponding author: Elnaz Khodapanah, Faculty of Petroleum and Natural Gas Engineering, Sahand Oil and Gas Research Institute, Sahand University of Technology, Sahand New Town, Tabriz, Iran, Postal Code: 5331817634, Tel: 984133459481; Email: ekhodapanah@yahoo.com

\section{Research Article \\ Volume 4 Issue 1}

Received Date: January 16, 2020

Published Date: February 28, 2020

DOI: $10.23880 /$ ppej-16000217

\section{Abstract}

Rock wettability plays an important role in water flooding process as it controls fluid flow, oil recovery and distribution of residual oil in any oil reservoir. In this context, polar oil components such as asphaltene contents may adsorb onto the pore mineral surfaces and alter wettability of the reservoir rock. Due to this importance, this study aims to investigate the effects of different parameters such as concentration of asphaltene, salinity, temperature and time on the rock wettability alteration process. For this purpose, dynamic contact angle measurement was performed. The results showed that the increment of asphaltene concentration in the oleic phase changes the wettability of water-wet sandstone rock to oil-wet condition; the increase in the concentration of asphaltene fraction from 0.1 to $5.0 \mathrm{~g} /$ lit increased the contact angle from 0 to 97 degrees. In addition, the increase in the brine salinity from 500 to $8000 \mathrm{ppm}$ increased the ability of asphaltene to adsorb on the rock surface and consequently, increased oil wetness; the equivalent contact angle changed from 0 to 113 degree for $5 \mathrm{~g} /$ lit asphaltene content after 192 hours. Moreover, the results illustrated that a rise in temperature from 40 to $70^{\circ} \mathrm{C}$ accelerates adsorption of asphaltene, but it has not significant effect on the final contact angle. Furthermore, the Adaptive Neuro-Fuzzy Inference System (ANFIS) is incorporated into the Particle Swarm Optimization (PSO) algorithm to correlate contact angle with the aforementioned parameters. To this end, the obtained experimental data are used to train and test the algorithm. The outputs of ANFIS-PSO algorithm are compared with the measured contact angles in both graphical and statistical manners. The training and testing determination coefficients $\left(\mathrm{R}^{2}\right)$ have been obtained as 0.99091 and 0.98761 , respectively. The analysis indicates that the predictive model can be used with a high degree of confidence to investigate the effect of different parameters on wettability alteration.

Keywords: Wettability of sandstone rocks; Contact angle; Asphaltene content; Salinity; ANFIS-PSO algorithm; Predicting model

\section{Introduction}

Wettability is known as one of the most important factors affecting the fluids distribution in reservoir pores [1]. Petroleum asphaltenes tend to adsorb onto solid interfaces which can cause noticeable problems during upstream and downstream operations, including oil recovery, production, pipeline transportation and refining of crude oil $[2,3]$. There are several mechanisms that can be involved in wettability alteration by crude oil adsorption: polar 


\section{Petroleum \& Petrochemical Engineering Journal}

interactions between oil components and solid, deposition or precipitation at the solid surface and acid/base or ionbinding interactions between ionized sites on the oil/brine and solid/brine interfaces [4]. It is believed that asphaltenes and other polar components of crude oils are responsible for rock wettability alteration. Asphaltenes are the most polar components and surface-active fractions of oil. Typically, the polar end of the asphaltene content is linked to the non-polar hydrocarbon (HC) molecules by functional groups including Nitrogen, Sulphur and Oxygen known as NSO hetero atoms. Nitrogen is commonly present as the basic and non-basic compounds such as pyridine, pyrrolic and quinolone. Sulphur compounds are present as sulfidic, sulfoxide or thiophene functional groups. Oxygen compounds consist of carboxyl, hydroxyl, and carbonyl groups [5,6]. Inorganic ions including $\mathrm{Ca}^{2+}, \mathrm{Mg}^{2+}, \mathrm{Na}^{+}$have a tendency to to break up water structure around the organic molecules, and hence, decrease the solubility of the organic components in water phase. Therefore, "salting-out effect" increases the preference of the organic materials in the oil phase or on solid surface. As a result, the likelihood of rock wettability alteration increases toward more oil wet conditions $[7,8]$. Fluid-rock interaction is significantly affected by temperature. Although contact angle is measured at constant temperature, some studies have also been conducted to examine the effect of temperature on contact angle. The experimental results revealed that contact angle increases by increasing temperature [9]. The solubility of asphaltene can be used to interpret the impact of temperature on contact angle. The influence of temperature on asphaltene solubility was investigated in the study conducted by Chandio, et al. [10]. They used six different crude oil samples at different temperatures ranging from 20 to $95{ }^{\circ} \mathrm{C}$. The results of their study showed that by increasing temperature asphaltene solubility increases. In addition to the temperature effect, other parameters such as presence or absence of the aqueous phase, surface chemistry, contact time and asphaltene content of the reservoir fluids also affect the wettability of the reservoir rock $[9,11]$.

Development of correlations for contact angle prediction as a function of effective parameters is of great importance in that it plays a significant impact on enhanced oil recovery processes. Akande et al. investigated the potential of a heuristic optimization procedure, known as Particle Swarm Optimization (PSO) technique, to optimize the selection of Support Vector machine Regression (SVR), as a computational intelligence method, to model and characterize hydrocarbon reservoirs. Their results showed the superior performance of the application of PSO in optimizing computational intelligence techniques applied in permeability prediction and reservoir characterization [12].

Zendehboudi et, al. also have approximated precipitation and deposition of asphaltene in the presence and without the presence of $\mathrm{CO}_{2}$ injection by combining the artificial neural networks (ANNs) with imperialist competitive algorithm (ICA) and PSO. They performed some dynamic tests and showed that pressure drop and temperature have the most significant effect on asphaltene deposition [13].

In the present study, initially the effects of different parameters including salinity, temperature, contact time and asphaltene content are investigated by a series of contact angle measurement tests. Furthermore, contact angle prediction and evaluation are performed using a novel Adaptive Neuro Fuzzy Inference System (ANFIS) incorporated into the Particle Swarm Optimization (PSO) algorithm. A brief summary of the present work is shown in Figure 1.

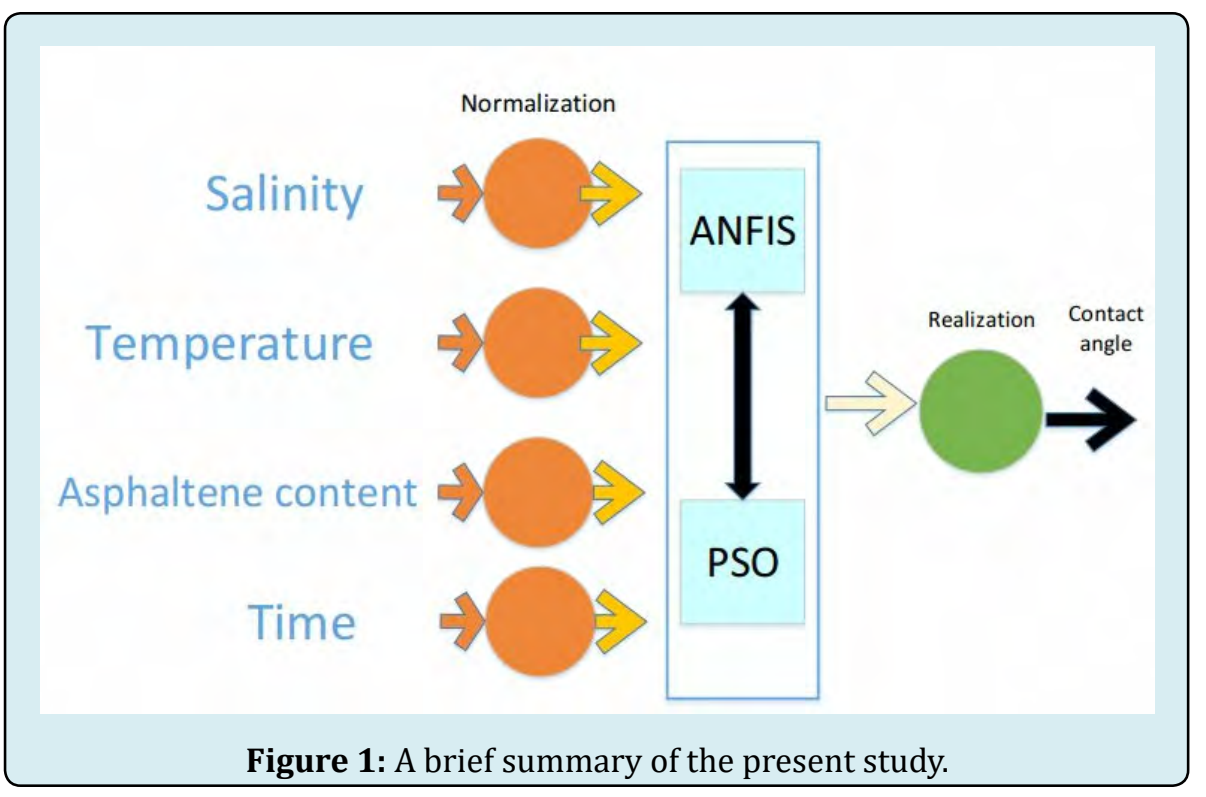

Khodapanah E, et al. Parametric Investigation of Wettability Alteration of Reservoir Rocks by Asphaltene Deposition: Experimental and Modeling Approaches. Pet Petro Chem Eng J 2020, 4(1): 000217. 


\section{Petroleum \& Petrochemical Engineering Journal}

\section{Methodology}

\section{Experimental Data}

In order to examine the influence of different parameters on the rock wettability alteration, a large number of experiments were performed using the contact angle technique on sandstone rocks. Asphaltene was extracted from an Iranian oilfield sample using ASTM-D6560 method $[14,15]$. Afterwards, asphaltene solutions were prepared by dissolving different concentrations of asphaltene (by weight percent) in Heptol solutions all consisting of $40 \%$ by volume $\mathrm{n}$-heptane and $60 \%$ by volume toluene. In order to measure the contact angle, sandstone rocks belonging to an Iranian formation were cut into $3 \mathrm{~cm} \times 2 \mathrm{~cm} \times 0.2 \mathrm{~cm}$ slices by a cutoff machine. The mineral compositions of the mentioned rock, determined by X-Ray diffraction technique, is shown in Figure 2. In addition, the porosity and permeability of the slices are in the range of $17 \%$ to $19 \%$ and 368 to $434 \mathrm{mD}$, respectively. The results demonstrated that the slices are composed mainly of quartz and feldspar. An end face grinder was also utilized to smooth the surfaces of the thin sections. Contact angle measurement setup consists of a light source, a computer, a syringe pump and a DinoLite digital microscope. The thin sections were aged in brine with different concentrations in the range of 500 to $8000 \mathrm{ppm}$ of $\mathrm{NaCl}$ for seven days at the room conditions. Then, the thin sections were put into an aquarium containing brine solutions and the initial contact angle was measured by injecting an oil droplet onto the rock surface. After this stage, the aged thin sections were placed in the heptol solutions with asphaltene contents in the range of 0.1 to $5 \mathrm{~g} / \mathrm{L}$ at $40^{\circ} \mathrm{C}$ and the contact angles were measured during the time period of 196 hours. In addition, to get further insight into the effect of temperature on wettability alteration, the contact angle measurement procedure was implemented using the asphaltene content of $5 \mathrm{~g} / \mathrm{L}$ and the brine salinity of $2000 \mathrm{ppm}$ at two different temperatures of 40 and $70^{\circ} \mathrm{C}$. Finally, a total dataset of 180 experimental contact angle data points were collected. In this study, the experimental error for the measured contact angle data is \pm 3 degrees. The parameters in the above-mentioned ranges were used as inputs to train and test the ANFIS-PSO algorithm. The input data including asphaltene content, contact time, temperature and salinity were normalized in the range of -1 to 1 to improve the training performance:

$$
D_{N}=2 \frac{D-D_{\min }}{D_{\max }-D_{\min }}-1
$$

Where $D$ is referred to as the input data, $\mathrm{D}_{\min }$ represents the minimum of the input data and denotes the maximum of the input data.

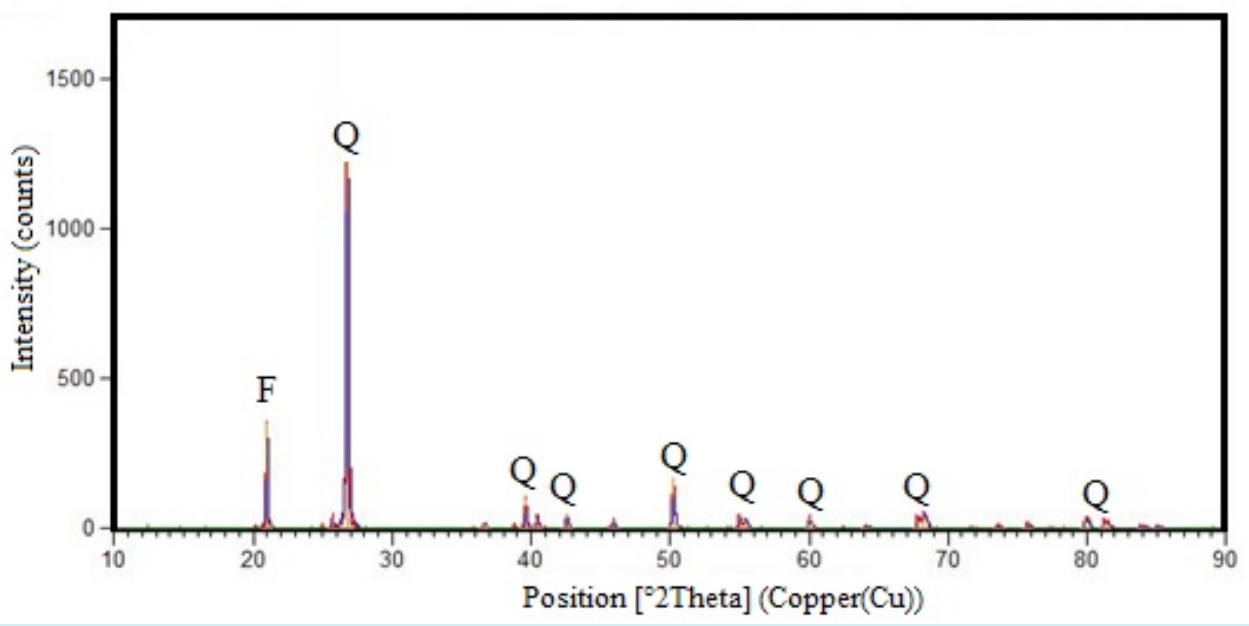

Figure 2: X-Ray diffraction analysis of the sandstone sample, Q: quartz, F: feldspar.

\section{Adaptive Neuro Fuzzy Inference System (ANFIS) and Particle Swarm Optimization (PSO) Algorithm}

ANFIS algorithm was developed based on utilizing Fuzzy logic and artificial neural network properties. ANFIS algorithm consists of different layers which are described in the following:

In the first layer, inputs are parameterized using the specific membership functions. The membership function selected in this study is the Gaussian function:

$$
O_{i}=\mu_{A i}(x), \forall \mathrm{i} \in\{1,2\}
$$




\section{Petroleum \& Petrochemical Engineering Journal}

$$
\begin{array}{r}
O_{i}^{1}=\mu_{B_{i-2}}(y), \forall \mathrm{i} \in\{3,4\} \\
\mu_{A i}(x)=e^{-\frac{\left(x-c_{i}\right)^{2}}{2 \sigma_{i}^{2}}}(4)
\end{array}
$$

Where $O_{i}^{j}$ denotes the $i^{\text {th }}$ output of the $j^{\text {th }}$ layer, $x$ and $y$ are known as the input data, $c$ and $\sigma$ represent the Gaussian indices. Typically, the outputs, and parameters are optimized in the training phase of the ANFIS model.

The second layer controls the accuracy of qualification which contains constant nodes and some weighted terms. The following equation represents the determination level:

$$
O_{i}^{2}=w_{i}=\mu_{A i}(x) \mu_{B i}(y), \forall \mathrm{i} \in\{1,2\}
$$

During the third layer, which is represented as the normalization layer, the mean values of the weighted terms of the second layer are calculated:

$$
O_{i}^{2}=\underline{w}_{i}=\frac{w_{1}}{w_{1}+w_{2}}, \forall \mathrm{i} \in\{1,2\}(6)
$$

The fourth layer is the stage where the Sugeno fuzzy rule function is multiplied by the output of the previous layer.

Sugeno fuzzy rule function: If $\left(x\right.$ is $\left.A_{i}\right)$ and ( $\mathrm{y}$ is $\left.B_{i}\right)$ then

$$
\begin{aligned}
f_{i}=p_{i} x+q_{i} y+r_{i}, \forall \mathrm{i} \in\{1,2\} \\
O_{i}^{4}=\underline{w}_{i} f_{i}=\underline{w}_{i}\left(p_{i} x+q_{i} y+r_{i}\right), \forall \mathrm{i} \in\{1,2\}
\end{aligned}
$$

where $p_{i}, q_{i}$ and $r_{i}$ are known as linear parameters. Finally, during the fifth layer, the calculation of the network output is performed using the weighted average summation method as the following:

$$
O_{i}^{5}=\sum_{i}^{5} \underline{w}_{i} f_{i}=\frac{\sum_{i}^{5} \underline{w}_{i} f_{i}}{\sum_{i}^{5} \underline{w}_{i}}
$$

For better understanding this algorithm, there are more details available in the literature [16-20].

To employ and complete the ANFIS algorithm, there is a powerful method namely particle swarm optimization (PSO) approach for optimization of all parameters [18]. The PSO approach applies a linear least squares technique to predict the premise parameters [21]. Initially, Eberhart and Kennedy [22] have proposed the PSO algorithm which is a populationbased stochastic optimization technique based on swarm.
This algorithm is inspired by the cooperative behavior of particles in which numerous particles with completely random positions are defined in a space with $\mathrm{N}$ dimensions and the position of the particles changes by increasing the iteration number, depending on the velocity updates [23]. After initializing, to get the best result and solution, each particle should adjust its velocity. In each iteration, every particle changes its position by considering its current velocity, position and all spaces including between the current and best positions [24].

\section{Results and Discussion}

As it was mentioned previously, the experimental and modeling approaches were adopted to investigate the effects of different parameters on contact angle phenomenon. For this reason, the potential of asphaltene to alter wettability of sandstone rock samples along with the effects of salinity, temperature and contact time on the asphaltene adsorption onto the rock surface were studied through contact angle measurements. Figure 3a shows the impact of asphaltene content on the contact angle of the aged samples in the presence of water with $\mathrm{NaCl}$ salinity of $2000 \mathrm{ppm}$, at the temperature of $40^{\circ} \mathrm{C}$. As the figure shows, by increasing the asphaltene content from 0.1 to $5 \mathrm{~g} / \mathrm{L}$, the contact angle increases to 97 degrees, which indicates that the wettability of the rock alters toward the oil-wet condition. Figure $3 \mathrm{~b}$ depicts the contact angle versus time of the aged rock samples with different concentrations of brine solution in the presence of heptol solution with asphaltene concentration of $5 \mathrm{~g} / \mathrm{L}$. As the figure shows, for $500 \mathrm{ppm}$ salinity, the slope of the contact angle versus time varies rapidly for about 24 hours. Then, the contact angle reaches nearly a constant value of 90 degrees after about 192 hours. Similar trends can be seen for the other samples where the potential of asphaltene content for changing sandstone wettability towards oil-wet condition increases as the salinity of brine increases. It is interesting to note that the contact angle changes from 0 to 102 degrees and from 0 to 113 degrees using 4000 and 8000 $\mathrm{ppm}$ of $\mathrm{NaCl}$ solutions, respectively. In fact, when the salinity of brine increases, the concentration of cations on the rock surface increases, which in turn increases the presence of polar components on the rock surface and changes the rock wettability.

Figure 3c illustrates the contact angle variation versus time at two different temperatures. In this case, the sandstone rock samples were aged with brine with $\mathrm{NaCl}$ salinity of $2000 \mathrm{ppm}$, which subsequently were placed in heptol solutions with asphaltene concentration of $5 \mathrm{~g} / \mathrm{L}$. As can be seen, at initial times, increasing the temperature from $40^{\circ} \mathrm{C}$ to $70^{\circ} \mathrm{C}$, the contact angle increases at the higher rate. As the time proceeds, the contact angle becomes stable and reaches a constant value in both experiments, after about 
96 hours from the beginning of the experiments. Although the increase in temperature accelerates the adsorption of asphaltene on the rock surface, it has a negligible impact on the equivalent contact angle.

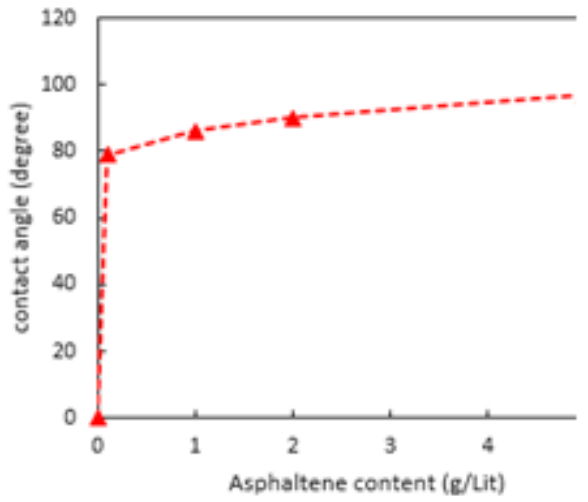

(a)

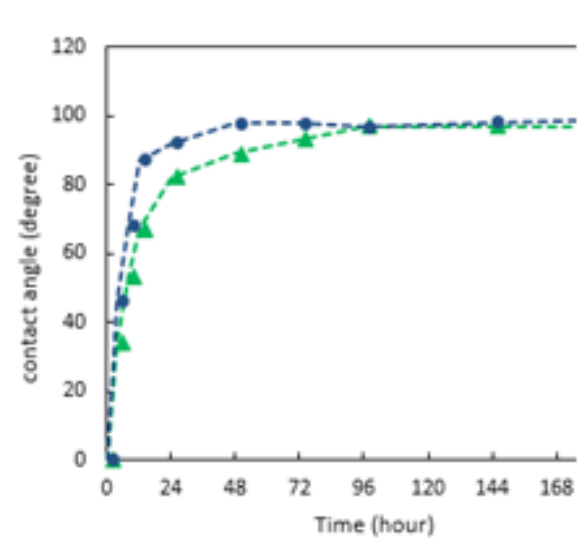

(c)

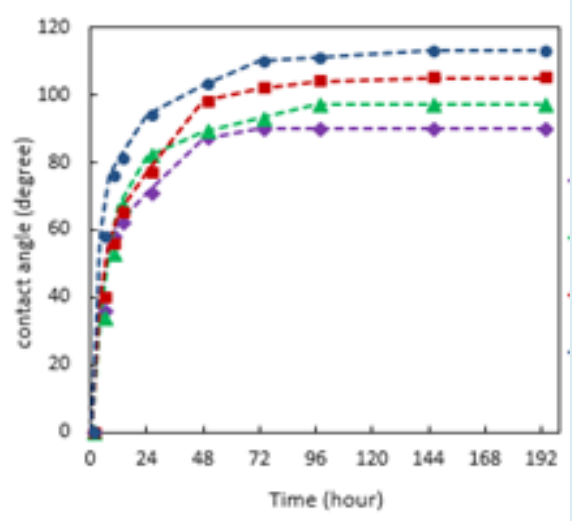

(b)

Figure 3: Effects of different parameters on the measured contact angle.

(a) contact angle of the aged rock with brine of $2000 \mathrm{ppm} \mathrm{NaCl}$ salinity versus asphaltene content at $40^{\circ} \mathrm{C}$.

(b) contact angle of the aged rock with different concentrations of brine, in heptol solution with asphaltene content of $5 \mathrm{~g} / \mathrm{L}$ at $40^{\circ} \mathrm{C}$.

(c)contact angle of the aged rock with brine of $2000 \mathrm{ppm} \mathrm{NaCl}$ salinity versus time, in heptol solution with asphaltene content of $5 \mathrm{~g} / \mathrm{L}$ at two different temperatures.

To get further understanding and prediction of the wettability alteration, the ANFIS-PSO algorithm was utilized to correlate the contact angle against the aforementioned parameters. In addition, to investigate the potential and performance of the mentioned algorithm, different analyses, such as graphical and statistical evolutionary approaches, were implemented. To accomplish this analysis, the determination coefficient $\left(\mathrm{R}^{2}\right)$ along with average absolute relative deviation (AARD) and root mean squared error (RMSE) were determined using the following formulas:

$$
\begin{gathered}
R^{2}=1-\frac{\sum_{i=1}^{N}\left(D_{i}^{\text {actual }}-D_{i}^{\text {predicted }}\right)^{2}}{\sum_{i=1}^{N}\left(D_{i}^{\text {actual }}-\underline{D^{\text {actual }}}\right)^{2}} \\
A A R D=\frac{100}{N} \sum_{i-1}^{N}\left|\frac{D_{i}^{\text {actual }}-D_{i}^{\text {predicted }}}{D_{i}^{\text {actual }}}\right| \\
R M S E=\sqrt{\frac{1}{N} \sum_{i=1}^{N}\left(D_{i}^{\text {actual }}-D_{i}^{\text {predicted }}\right)^{2}}
\end{gathered}
$$




\section{Petroleum \& Petrochemical Engineering Journal}

Where $D_{i}^{\text {actual }}$ is referred to as the target value (experimentally

measured contact angle), $D_{i}^{\text {predicted }}$ denotes the output of the

model and represents the total number of data points.

The computed values of $\mathrm{R}^{2}$, AARD and RMSE are given in Table 1 for different phases of the ANFIS-PSO algorithm. The determined indices illustrate the accuracy of the ANFIS-PSO algorithm in predicting the effect of different parameters on wettability alteration. Figure 4 depicts a comparison between the ANFIS-PSO and the experimental contact angles. The predicted values lie upon contact angle data points obtained from experiments with a high accuracy. As Figure 4 shows, excellent agreements have been obtained between experimental and predicted contact angles using the ANFISPSO algorithm. Moreover, for better representation of this fact, the predicted contact angle is depicted versus the measured contact angle in Figure 5. As can be seen, the data points are almost close to the line described by $y=x$ which confirms the previous results. Another graphical manner to evaluate the
ANFIS-PSO algorithm is calculating the relative deviation of the predicted contact angles using the ANFIS-PSO algorithm from the measured data. According to Figure 6, the relative deviation points lie closely on the line indicating the efficient potential of the proposed model in predicting the contact angle. Eventually, Figure 7 demonstrates the bar chart of the residual, defined as the difference between measured and predicted contact angle, for both achieved datasets during training and testing phases. The concentration of the residuals near zero again represents the high degree of accuracy of the ANFIS-PSO algorithm in predicting the contact angle.

\begin{tabular}{|c|c|c|c|}
\hline & $\begin{array}{c}\text { Training } \\
\text { Dataset }\end{array}$ & $\begin{array}{c}\text { Testing } \\
\text { Dataset }\end{array}$ & $\begin{array}{c}\text { Total } \\
\text { Dataset }\end{array}$ \\
\hline RMSE & 2.8018 & 3.5452 & 2.9440 \\
\hline AARD (\%) & 2.0539 & 2.1636 & 2.0589 \\
\hline $\mathrm{R}^{2}$ & 0.99091 & 0.98761 & 0.99013 \\
\hline
\end{tabular}

Table 1: Statistical parameters of different datasets.

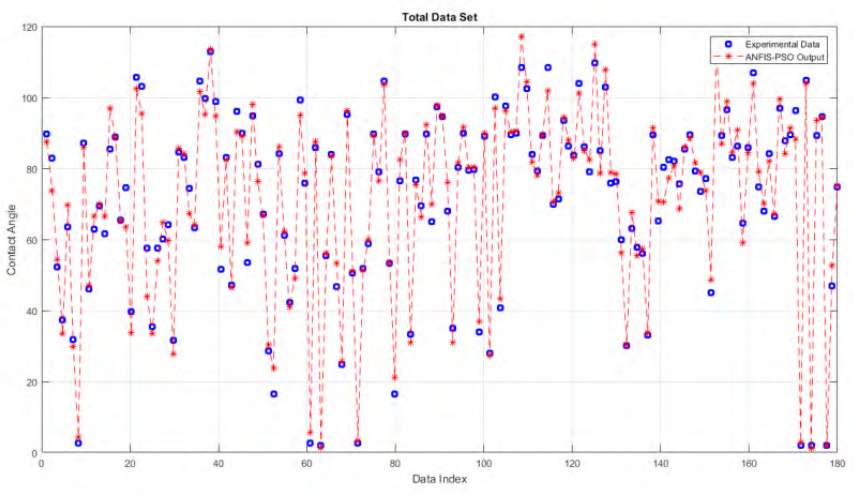

Figure 4: Comparison between experimental and predicted contact angles using the ANFIS-PSO algorithm.

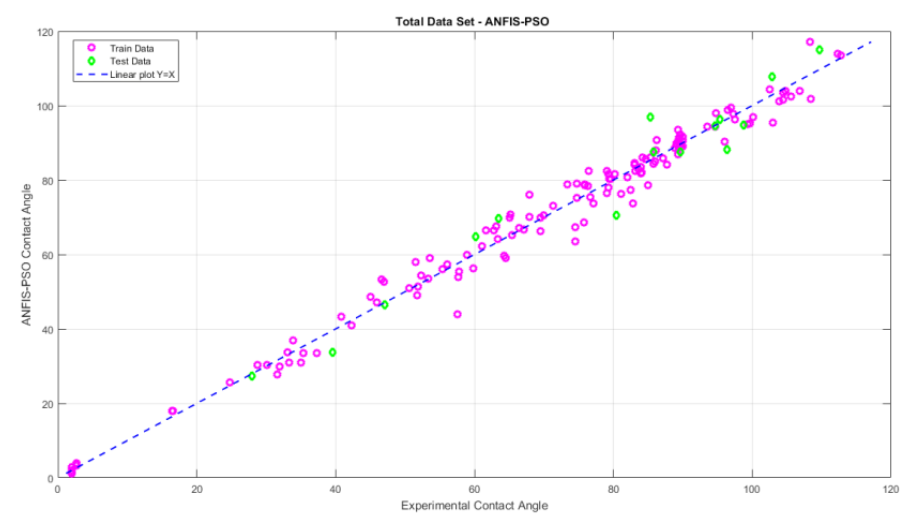

Figure 5: Predicted contact angle using the ANFIS-PSO algorithm versus the experimental contact angle. 


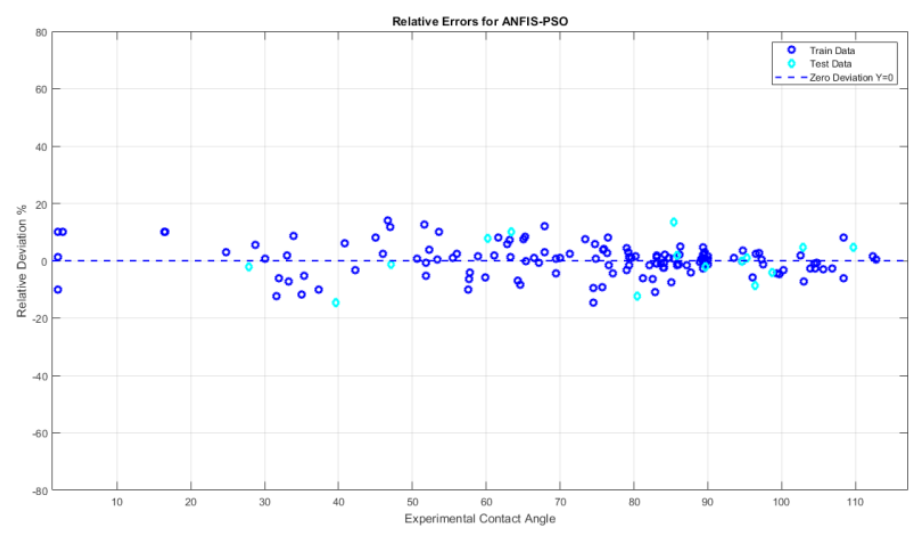

Figure 6: Relative deviation distribution of the contact angle in different phases of the ANFIS-PSO algorithm.

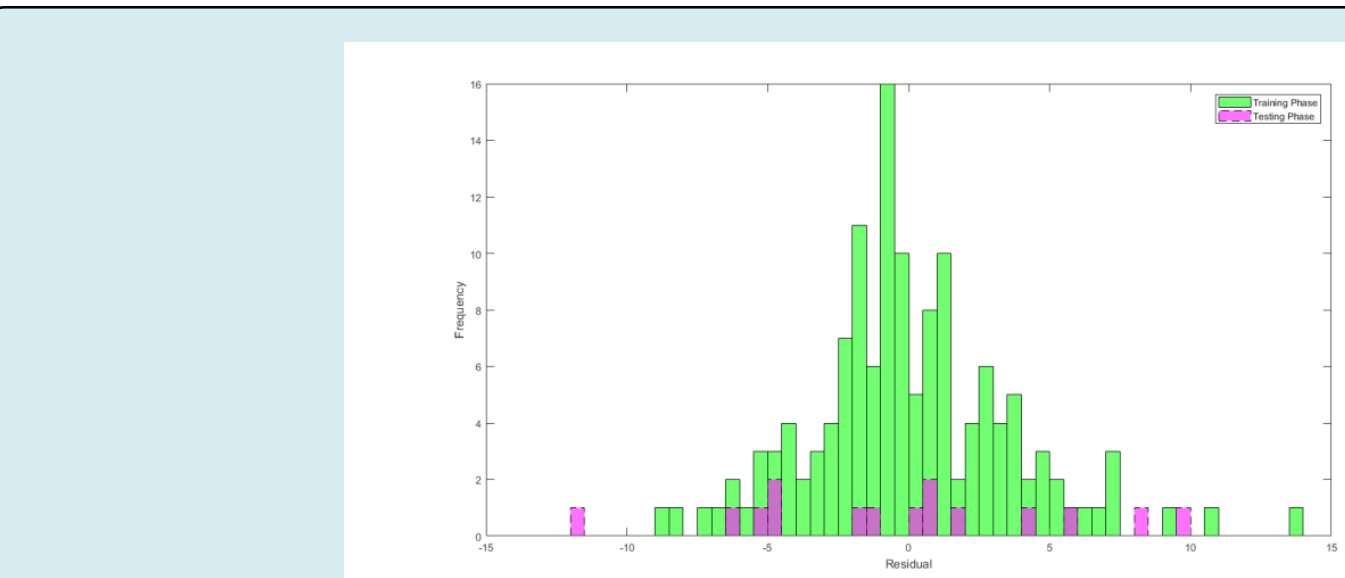

Figure 7: The differences between experimental and predicted contact angles (residuals) using ANFIS-PSO algorithm.

\section{Conclusions}

In the present study, the effect of different parameters including asphaltene content, salinity, temperature and time on wettability alteration were investigated by contact angle measurement. The results indicated that the asphaltene content of oil has a significant potential for changing rock wettability to more oil-wet condition in sandstone rocks in which increasing the concentration of asphaltene from 0.1 to $5.0 \mathrm{~g} /$ lit increased contact angle from 0 to 97 degrees. Also, the results demonstrated that the brine salinity has a noticeable impact on the adsorbed asphaltene content onto the rock surface, and causes the wettability alteration to more oil-wet condition. Furthermore, the experiments revealed that rising temperature from 40 to $70^{\circ} \mathrm{C}$ speeds up the adsorption of asphaltene components on the rock surface, but it cannot alter the equivalent contact angle. In addition, a novel algorithm based on Adaptive Neuro Fuzzy
Inference System coupled with Particle Swarm Optimization (ANFIS-PSO) algorithm was developed to get further understanding of the aforementioned effects. The predicting model was trained and validated by utilizing the measured data. Different manners such as statistical and graphical approaches were applied to analyze the proposed model. The determination coefficients $\left(\mathrm{R}^{2}\right)$ of 0.99149 and 0.98698 were obtained, respectively, in training and testing phases of the algorithm. Finally, comparisons of the training and testing outputs with the experimental data indicated that the ANFIS-PSO has high potential to be used in predicting rock and fluid properties.

\section{References}

1. Anderson WG (1987) Wettability literature survey-part 6: the effects of wettability on waterflooding. Journal of petroleum technology 39(12): 1-605. 


\section{Petroleum \& Petrochemical Engineering Journal}

2. Tabatabaei-Nejad SAR, Khodapanah E (2010) Application of Chebyshev Polynomials to Predict Phase Behavior of Fluids Containing Asphaltene and Associating Components Using SAFT Equation of State. Fuel 89(9): 2511-2521.

3. Tabatabaei-Nejad SAR, Khodapanah E (2012) Application of Chebyshev Polynomials to Calculate Density and Fugacity Using SAFT Equation of State to Predict Asphaltene Precipitation Conditions. Advances in Chemical Engineering. InTech.

4. Buckley JS, Liu Y, Monsterleet S (1998) Mechanisms of wetting alteration by crude oils. SPE journal 3(1): 54-61.

5. Adams JJ (2014) Asphaltene adsorption, a literature review. Energy \& Fuels 28(5): 2831-2856.

6. Mullins OC, Sheu EY (2013) Structures and dynamics of asphaltenes. Springer US, pp: 438.

7. Standal S, Haavik J, Blokhus AM, Skaugeb A (1999) Effect of polar organic components on wettability as studied by adsorption and contact angles. Journal of Petroleum Science and Engineering 24(2-4): 131-144.

8. Lashkarbolooki M, Ayatollahi S, Riazi M (2014) Effect of salinity, resin, and asphaltene on the surface properties of acidic crude oil/smart water/rock system. Energy \& Fuels 28(11): 6820-6829.

9. Alotaibi MB, Nasralla RA, Nasr-El-Din HA (2011) Wettability studies using low-salinity water in sandstone reservoirs. SPE Reservoir Evaluation \& Engineering 14(6): 713-725.

10. Chandio ZA, Ramasamy M, Mukhtar HB (2015) Temperature Effects on Solubility of Asphaltenes in Crude Oils. Chemical Engineering Research and Design 94: 573-583.

11. Dixit AB, McDougall SR, Sorbie KS, Buckley JS (1996) Pore scale modelling of wettability effects and their influence on oil recovery. SPE/DOE Improved Oil Recovery Symposium, Society of Petroleum Engineers, USA.

12. Akande KO, Owolabi TO, Olatunji SO, AbdulRaheem AA (2017) A hybrid particle swarm optimization and support vector regression model for modelling permeability prediction of hydrocarbon reservoir. Journal of Petroleum Science and Engineering 150: 4353.

13. Zendehboudi S, Shafiei A, Bahadori A, James LA, Elkamel A, et al. (2014) Asphaltene Precipitation and Deposition in Oil Reservoirs-Technical Aspects, Experimental and Hybrid Neural Network Predictive Tools. Chemical
Engineering Research and Design 92(5): 857-875.

14. ASTM D6560 (2000) Standard Test Method for Determination of Asphaltenes (Heptane Insolubles) in Crude Petroleum and Petroleum Products. ASTM International, West Conshohocken, PA.

15. Bisht H, Reddy M, Malvanker M, Patil RC, Gupta A, et al. (2013) Efficient and quick method for saturates, aromatics, resins, and asphaltenes analysis of whole crude oil by thin-layer chromatography-flame ionization detector. Energy \& Fuels 27(6): 3006-3013.

16. Baghban A, Sasanipour J, Haratipour P, Alizad M, Ayouri MV (2017) ANFIS modeling of rhamnolipid breakthrough curves on activated carbon. Chemical Engineering Research and Design 126: 67-75.

17. Barati-Harooni A, Najafi-Marghmaleki A, Mohammadi AH (2016) ANFIS modeling of ionic liquids densities. Journal of Molecular Liquids 224(Part A): 965-975.

18. Keybondorian E, Taherpour A, Bemani A, Hamule T (2018) Application of novel ANFIS-PSO approach to predict asphaltene precipitation. Petroleum Science and Technology 36(2): 154-159.

19. Malmir P, Suleymani M, Bemani A (2018) Application of ANFIS-PSO as a novel method to estimate effect of inhibitors on Asphaltene precipitation. Petroleum Science and Technology 36(8): 597-603.

20. Suleymani M, Bemani A (2018) Application of ANFISPSO algorithm as a novel method for estimation of higher heating value of biomass. Energy Sources, Part A: Recovery, Utilization, and Environmental Effects 40(3): 288-293.

21. Banashooshtari H, Ashtari Larki S, Shokrollahzadeh Behbahani H (2018) A PSO-ANFIS framework for prediction of density of bitumen diluted with solvents. Petroleum Science and Technology 36(2): 122-129.

22. Eberhart R, Kennedy J (1995) A new optimizer using particle swarm theory. In MHS'95. Proceedings of the Sixth International Symposium on Micro Machine and Human Science, Japan, pp: 39-43.

23. Wang D, Tan D, Liu L (2018) Particle swarm optimization algorithm: an overview. Soft Computing, 22(2): 387-408.

24. Clerc M, Kennedy J (2002) The particle swarm-explosion, stability, and convergence in a multidimensional complex space. IEEE transactions on Evolutionary Computation 6(1): 58-73. 